\title{
Fatty acid positional distribution (sn-2 fatty acids) and phospholipid composition in Chinese breast milk from colostrum to mature stage
}

\author{
Ke $\mathrm{Wu}^{1} \dagger$, Runying $\mathrm{Gao}^{1} \dagger$, Fang $\mathrm{Tian}^{2}$, Yingyi $\mathrm{MaO}^{2}$, Bei $\mathrm{Wang}^{3}$, Lili Zhou ${ }^{3}$, Liwei Shen ${ }^{3}$, Yan Guan ${ }^{2 *}$ \\ and Meiqin $\mathrm{Cai}^{1 *}$ \\ ${ }^{1}$ School of Public Health, Shanghai Jiao Tong University, Shanghai 200025, People's Republic of China \\ ${ }^{2}$ Abbott Nutrition Research \& Development Center, Abbott Ltd, Shanghai 200233, People's Republic of China \\ ${ }^{3}$ Department of Gynecology and Obstetrics, Xinhua Hospital, School of Medicine, Shanghai Jiao Tong University, \\ Shanghai 200092, People's Republic of China
}

(Submitted 29 May 2018 - Final revision received 3 August 2018 - Accepted 18 September 2018 - First published online 31 October 2018)

\section{Abstract}

This study quantified the fatty acid profile with emphasis on the stereo-specifically numbered (sn) 2 positional distribution in TAG and the composition of main phospholipids at different lactation stages. Colostrum milk ( $n$ 70), transitional milk $(n$ 96) and mature milk $(n 82)$ were obtained longitudinally from healthy lactating women in Shanghai. During lactation, total fatty acid content increased, with SFA dominating in fatty acid profile. A high ratio of $n-6: n-3$ PUFA was observed as 11:1 over lactation due to the abundance of linoleic acid in Chinese human milk. As the main SFA, palmitic acid showed absolute $s n$ - 2 selectivity, while oleic acid, linoleic acid and $\alpha$-linolenic acid, the main unsaturated fatty acids, were primarily esterified at the $s n-1$ and $s n-3$ positions. Nervonic acid and C22 PUFA including DHA were more enriched in colostrum with an $s n-2$ positional preference. A total of three dominant phospholipids (phosphatidylethanolamine (PE), phosphatidylcholine (PC) and sphingomyelin (SM)) were analysed in the collected samples, and each showed a decline in amount over lactation. PC was the dominant compound followed by SM and PE. With prolonged breast-feeding time, percentage of PE in total phospholipids remained constant, but PC decreased, and SM increased. Results from this study indicated a lipid profile different from Western reports and may aid the development of future infant formula more suitable for Chinese babies.

\section{Key words: Human breast milk: Lipid profiles: sn-2 Fatty acids: Phospholipids: Lactation stages}

Human breast milk from healthy, well-nourished mothers is considered as the ideal nourishment to fulfil nutritional and physiological needs of full-term infants in the first 6 months ${ }^{(1)}$. Among all provided nutrients, human milk lipids contribute approximately $50 \%$ of total energy and are also essential for the developing organs of infants to achieve an accelerated growth.

TAG, the major form of lipids in human milk (approximately $98 \%$ ), contain a special composition of SFA, MUFA and PUFA. These fatty acids are selectively esterified to the glycerol skeleton at three stereo-specifically numbered $(s n)$ positions in human milk, and the proportion of $s n$ - 2 to $s n-1,3$ can significantly affect the uptake, metabolism and tissue distribution of fatty acids ${ }^{(2)}$.

The most common SFA, palmitic acid (PA, C16:0), is mainly esterified at the $s n-2$ position. The abundance of 2 -mono-palmitins in human milk has been correlated with significant roles in infant health, including fatty acid and Ca absorption, bone health, gut microbes and infant comfort ${ }^{(2,3)}$. In human milk, high amount of unsaturated fatty acids such as oleic acid (OA, C18: $1 n$-9), linoleic acid (LA, C18:2n-6) and $\alpha$-linolenic acid (ALA, C18:3n-3) are preferentially distributed at the outer $s n$ 1,3 positions. Long-chain PUFA (LC-PUFA) consist only a very small part of human milk lipids but have been largely evidenced to provide immune and brain development benefits, especially arachidonic acid (AA, C20:4n-6), DHA (C22:6n-3) and adrenic acid $(\mathrm{C} 22: 4 n-6)^{(4,5)}$. Recent studies have also suggested that nervonic acid (NA, C24:1n-9) functions crucially in cognition development ${ }^{(6)}$. The positional distribution patterns of NA and LC-PUFA related to brain development were less investigated, and most available data ${ }^{(7-12)}$ reported the $s n-2$ fatty acid composition as a percentage of total $s n-2$

Abbreviations: AA, arachidonic acid; ALA, $\alpha$-linolenic acid; CM, colostrum milk; DPA, docosapentaenoic acid; LA, linoleic acid; LC-PUFA, long-chain PUFA; MM, mature milk; NA, nervonic acid; OA, oleic acid; PA, palmitic acid; PC, phosphatidylcholine; PE, phosphatidylethanolamine; PL, phospholipid; SM, sphingomyelin; TM, transitional milk.

* Corresponding authors: Y. Guan, email yan.guan@abbott.com; M. Cai, email caimeiqin@sjtu.edu.cn

$\dagger$ Contributed equally to this work. 
fatty acid without consideration of the total percentage of each fatty acid as recommended ${ }^{(7,9)}$.

Phospholipids (PL) contribute $0 \cdot 2-2 \cdot 0 \%$ of total human milk lipids. The dominant PL can be classified into five types, including phosphatidylethanolamine (PE), phosphatidylcholine (PC), sphingomyelin (SM), phosphatidylinositol and phosphatidylserine of which the former three consist $62-80 \%$ of PL in human milk ${ }^{(13,14)}$. PL function in both the structural formation and the stability maintenance of milk fat globule membrane ${ }^{(13,14)}$. In addition, PL are considered essential for optimum development of infant brain as an important source of LC-PUFA and choline.

Lipid profile in human milk changes with lactation stages and varies among different geographical regions due to diverse dietary patterns and genetic backgrounds ${ }^{(15-17)}$. Previous Chinese breast milk studies demonstrated different fatty acid and PL composition from Western reports, but the intra-molecular distribution of fatty acids has not been detailed yet. Geographically representative breast milk from healthy, well-nourished mothers should be considered as the golden reference in the development of localised baby formulas ${ }^{(10)}$. Shanghai, the most developed city with diverse population and great infant development, is ideal for Chinese human milk study.

The aim of this study was to determine the lipid profile of human breast milk collected longitudinally at different lactation stages (colostrum milk (CM), transitional milk (TM) and mature milk (MM)) from healthy mothers living in Shanghai, China. The fatty acid composition was analysed with the emphasis on the $s n-2$ fatty acid distribution. The PL composition and change trends over lactation stages were also determined and discussed.

\section{Methods}

\section{Subjects and milk samples collection}

Lactating mothers were recruited from the Labour and Delivery Unit in Xinhua Hospital affiliated to Shanghai Jiao Tong University School of Medicine, Shanghai, China. Subjects were breast-feeding mothers aged between 18 and 35 years old and of full-term, singleton delivery with breastfeeding planned for more than 2 months. Exclusion criteria included diabetes, hypertension, communicable diseases and congenital abnormalities. Smoking and drinking were also excluded.

Mothers were asked to provide CM (1-5 d post-partum), TM (11-15 d post-partum) and MM (41-45 d post-partum). About $2 \mathrm{~h}$ after the first morning feeding, both sides of the mammary gland were evacuated completely with an electric breast pump, and the milk was carefully mixed. A proportion of whole breast milk was taken $(5-10 \mathrm{ml}$ for $\mathrm{CM}$ and $10-15 \mathrm{ml}$ for TM and $\mathrm{MM}$ ) and immediately transported to the freezer $\left(-80^{\circ} \mathrm{C}\right)$, while the remaining milk was fed to the infants. Shanghai Xinhua Hospital Ethics Committee approved all aspects of the study, and informed consent was obtained from all the participants.

\section{Fatty acid and sn-2 fatty acid analysis}

Lipids were extracted from milk samples $(2 \mathrm{ml})$ using the method published by Folch et $a l^{(18)}$ with some modifications. Dichloromethane-methanol-petroleum ether $\left(30-60^{\circ} \mathrm{C}\right)(2: 1: 2$, by vol.; $20 \mathrm{ml}$ ) was used as the reagent to obtain lipid extract. The extraction solution was collected and evaporated to dryness with $\mathrm{N}_{2}$ flushing. The extract was re-dissolved in $2 \mathrm{ml}$ of hexane, of which $600 \mu \mathrm{l}$ was used to determine the fatty acid profile, and the remaining was used to analyse the $s n$ - 2 fatty acid composition.

For the analysis of fatty acid profile, $2 \mathrm{ml}$ of hexane was added into the 600- $\mu \mathrm{l}$ lipid solution, and an accurate amount of tritridecanoin (4 mg for each sample) (C13:0; Nu-Chek-Prep) was added as internal standard. The mixture was then transesterified with $2 \mathrm{ml}$ sodium methoxide methanol solution ( $0.5 \mathrm{M}$; Sigma-Aldrich), and the generated fatty acid methyl ethers (FAME) were then extracted with hexane. Saturated $\mathrm{NaCl}$ solution $(2 \mathrm{ml})$ was added to facilitate the layer separation. The clear upper phase was purified through a nylon organic-phase needle filter $(0.22 \mu \mathrm{m}$; Anpel) and subjected to fatty acid profile analysis.

Hydrolysis of TAG to 2-monoacylglycerol was carried out according to the method described by Luddy et al. ${ }^{(19)}$. In brief, the $1400 \mu \mathrm{l}$ lipid extract was evaporated under $\mathrm{N}_{2}$ to dryness and re-dissolved in $200 \mu \mathrm{l}$ of anhydrous diethyl ether, and TRIS buffer ( $\mathrm{pH} 8.0,6 \mathrm{ml})$, bile salts $(0.05 \%, 1.5 \mathrm{ml})$, calcium chloride $(2.2 \%, 0.6 \mathrm{ml})$ and pancreatic lipase (porcine pancreatic lipase type II, $20 \mathrm{mg}$ ) were then added successively. The mixture was mixed well and incubated in a shaking air bath (Innova 40; New Brunswick) under $40^{\circ} \mathrm{C}$ for $5 \mathrm{~min}$ at $240 \mathrm{rpm}$. Then $\mathrm{HCl}$ solution $(6 \mathrm{~m}, 2 \mathrm{ml})$ was added to stop the reaction. Diethyl ether $(4 \mathrm{ml})$ was used to transfer the sample solution to a $15-\mathrm{ml}$ centrifuge tube. The mixture was then vortexed for $30 \mathrm{~s}$ and subjected to centrifugation at $6000 \mathrm{rpm}$ for $3 \mathrm{~min}$. The obtained clear upper phase was collected and evaporated under $\mathrm{N}_{2}$ to dryness. The residue containing TAG, diacylglycerols, 2-monoacylglycerols and NEFA was re-dissolved in $0.5 \mathrm{ml}$ of methanol-chloroform $(1: 2, \mathrm{v} / \mathrm{v})$ and followed by purification with a silica solid-phase extraction cartridge ( $1 \mathrm{~g}, 6 \mathrm{ml}$; Anpel). Hexane $(30 \mathrm{ml})$ was used to equilibrate the cartridge, and hexane $(8 \mathrm{ml})$, hexane-diethyl ether $(0 \cdot 95: 0 \cdot 05, \mathrm{v} / \mathrm{v} ; 12 \mathrm{ml})$ and hexane-diethyl ether $(0 \cdot 90: 0 \cdot 10, \quad \mathrm{v} / \mathrm{v} ; 4 \mathrm{ml})$ were used successively to elute the TAG, NEFA and diacylglycerols, respectively. The 2-monoacylglycerols were eluted finally with methanol (12 ml), and the elute was collected and evaporated to dryness under $\mathrm{N}_{2}$. The residue was re-dissolved in $2 \mathrm{ml}$ of hexane and subjected to the same trans-esterification procedure as the fatty acid profile analysis.

The FAME sample solutions obtained earlier was analysed by GC with flame ionisation detector ${ }^{(20)}$ (Agilent 7890B). The separation was performed on a capillary column (Supelco 2560, $100 \mathrm{~m} \times 0.25 \mathrm{~mm} \times 0.20 \mu \mathrm{m}$; Sigma-Aldrich). Both the injector and the detector temperatures were $250^{\circ} \mathrm{C}$. Helium was used as the carrier gas with a flow rate of $0.8 \mathrm{ml} / \mathrm{min}$ and split ratio was 1:20. The column oven temperature program was as follows: $100^{\circ} \mathrm{C}$ for the first $13 \mathrm{~min}$, followed by an increase of $10^{\circ} \mathrm{C} / \mathrm{min}$ to $180^{\circ} \mathrm{C}$ and maintained for $6 \mathrm{~min}$, and subsequently elevated 
to $200^{\circ} \mathrm{C}$ at the rate of $1^{\circ} \mathrm{C} / \mathrm{min}$ and maintained for $20 \mathrm{~min}$ and finally increased by $4^{\circ} \mathrm{C} / \mathrm{min}$ until reaching $230^{\circ} \mathrm{C}$ and maintained at this temperature for $13.5 \mathrm{~min}$. The FAME were identified by comparing retention times of sample peaks with those of a mixed FAME standard (GLC-746; Nu-Chek-Prep) and calculated using the internal standard added to the samples at the very beginning of pre-treatment.

\section{Phospholipids analysis}

PL were extracted according to modified Folch extraction ${ }^{(18)}$. Briefly, $0.75 \mathrm{~g}$ of maternal milk was weighed into a test tube and extracted with chloroform-methanol (2:1, v/v; $4.5 \mathrm{ml})$, and $0.5 \mathrm{ml}$ saturated $\mathrm{NaCl}$ solution was then added to facilitate the layer separation. The lower organic phase was separated and collected after centrifugation at $6000 \mathrm{rpm}$ for $5 \mathrm{~min}$. The extraction was repeated one more time, and the organic phases were combined and evaporated to dryness under $\mathrm{N}_{2}$. The crude extract was dissolved in chloroform-methanol $(2: 1, \mathrm{v} / \mathrm{v} ; 1 \mathrm{ml})$ and further purified by a silica cartridge (Sep-Pak $500 \mathrm{mg}, 6 \mathrm{ml}$; Waters). After equilibration with hexane $(40 \mathrm{ml})$, non-polar lipids were eluted first by hexane-diethyl ether $(1: 4, \mathrm{v} / \mathrm{v} ; 3 \mathrm{ml})$ and hexane-diethyl ether $(1: 1, \mathrm{v} / \mathrm{v} ; 3 \mathrm{ml})$. The PL were then eluted with methanol ( $4 \mathrm{ml}$ ) and chloroform-methanol-water (3:5:2, by vol.; $2 \mathrm{ml}$ ) and evaporated to dryness under $\mathrm{N}_{2}$. The PL were then re-dissolved in chloroform-methanol $(1: 2, \mathrm{v} / \mathrm{v} ; 200 \mu \mathrm{l})$ and filtered through a polytetrafluoroethylene membrane filter $(0 \cdot 20 \mu \mathrm{m}$; Anpel).

The PL sample solutions obtained earlier were analysed by HPLC with variable wavelength detector (Agilent 1260 Infinity; Agilent). The separation was performed on a normal-phase column (ZORBAX RX-SIL, $4.6 \mathrm{~mm} \times 250 \mathrm{~mm} \times 5 \mu \mathrm{m}$; Agilent). The mobile phase was a mixture of methanol, phosphoric acid (85\%; Sigma-Aldrich) and acetonitrile (32:0·6:67.4, by vol.) at a flow rate of $1 \mathrm{ml} / \mathrm{min}$. The column temperature was at $30^{\circ} \mathrm{C}$, and the wavelength of the detector was set at $205 \mathrm{~nm}$. PE, PC and SM were analysed and quantified using standard curves (standards all from Sigma-Aldrich).

\section{Statistical analysis}

The results were reported as means and standard deviations and analysed with SPSS 20.0 (SPSS). Data were first checked for normality with the Kolmogorov-Smirnov test. When the variables were normally distributed, one-way ANOVA was adopted to evaluate differences at the significance level of $0 \cdot 05$, and then a comparison between any two means of the lactation stage was performed by a Bonferroni test if the results of ANOVA were significant. Otherwise, a non-parametric Kruskal-Wallis test was used.

\section{Results}

\section{Basic characteristics}

A total of 100 mothers provided at least one sample while sixtyeight provided three samples. A total of 248 milk samples including seventy CM, ninety-six TM and eighty-two MM samples were collected. The main characteristics of the sampled mothers and respective newborns are shown in Table 1. All mothers were Han Chinese. For newborns, fifty-five were delivered by caesarean section, and the others were born vaginally.

\section{Fatty acid and sn-2 fatty acid composition over lactation}

Fatty acid composition (FA\%, w/w) described individual fatty acid in total fatty acids, and $s n-2$ fatty acid composition ( $s n-2 \%$, $\mathrm{w} / \mathrm{w}$ ) described a specific fatty acid at $s n-2$ position compared with the total amount of this fatty acid (relative percentage of each fatty acid in $s n-2$ position). An overall fatty acid composition is shown in Table 2, and the detailed fatty acid profiles (FA\% and $s n-2 \%$ ) are presented in Table 3 (SFA, twelve types), Table 4 (MUFA, five types) and Table 5 (PUFA, eleven types).

The amount of total fatty acids showed a significant increment for three stages $(P<0 \cdot 001)$ as CM $(15 \cdot 20(\mathrm{sD} 7 \cdot 21) \mathrm{mg} / \mathrm{g}$ human milk), TM (29.55 (sD 8.98) mg/g human milk) and MM $(32.55$ ( $\mathrm{SD} 12.79) \mathrm{mg} / \mathrm{g}$ human milk), while the change in percentage of total SFA, total MUFA, total PUFA and individual fatty acid appeared differently (Table 2). SFA were the most abundant fatty acids in human milk that the percentage of SFA was slightly higher than MUFA and about 10\% higher than PUFA (SFA:MUFA:PUFA $=$ approximately $1 \cdot 4: 1 \cdot 3: 1$ in $\mathrm{CM}$ and $\mathrm{MM}$; approximately $1 \cdot 6: 1 \cdot 2: 1$ in TM). A higher percentage of SFA was reported in TM together with a lower percentage of MUFA. Percentages of total PUFA, $n-6$ PUFA and $n-3$ PUFA, were all constant over lactation stages, and stable levels were also seen in the ratios of $n-6: n-3$ (approximately 11), LA:ALA (approximately 19) and AA:DHA (approximately $1 \cdot 3$ ).

\section{Fatty acid and sn-2 fatty acid composition of SFA}

PA was the dominant SFA in content (approximately $20 \%$ of total fatty acids), and lauric acid (C12:0), myristic acid (C14:0) and stearic acid (C18:0) were $2-6 \%$ of total fatty acids, while C6: 0 , C8: 0 and C24: 0 only consisted a very small part $(<1.0 \%)$ of total milk fat. TAG in TM and MM contained higher level of short-chain (C6:0) and medium-chain SFA (C8-C14) but lower level of longchain SFA (C15-C24). Interestingly, the relative proportion of SFA at the $s n-2$ position increased considerably from C10:0 to C16:0. Around $55 \%$ of myristic acid, $65 \%$ of $\mathrm{C} 15: 0$ and $75 \%$ of PA were distributed at the $s n-2$ position, while the other types of SFA were selectively located at the $s n-1,3$ positions.

Table 1. Characteristics of the sampled 100 mothers and respective newborns

(Mean values, standard deviations and ranges)

\begin{tabular}{|c|c|c|c|}
\hline Characteristics & Mean & SD & Range \\
\hline Age (years) & $30 \cdot 0$ & $3 \cdot 0$ & $22-35$ \\
\hline Gestational period (weeks) & $39 \cdot 0$ & $1 \cdot 0$ & $37-41$ \\
\hline Parity & $1 \cdot 2$ & 0.4 & $1-2$ \\
\hline BMI $\left(\mathrm{kg} / \mathrm{m}^{2}\right)$, pre-gestation & $20 \cdot 7$ & $2 \cdot 2$ & $15 \cdot 6-28 \cdot 3$ \\
\hline BMI $\left(\mathrm{kg} / \mathrm{m}^{2}\right)$, pre-delivery & $27 \cdot 2$ & 2.8 & $19 \cdot 2-35 \cdot 1$ \\
\hline Weight of the newborns $(\mathrm{g})$ & 3377 & 360 & $2285-4360$ \\
\hline Length of the newborns $(\mathrm{cm})$ & $49 \cdot 6$ & $1 \cdot 2$ & $46 \cdot 0-53 \cdot 0$ \\
\hline $\begin{array}{l}\text { Head circumference of the } \\
\text { newborns }(\mathrm{cm})\end{array}$ & 34.5 & 1.0 & $32 \cdot 0-37 \cdot 5$ \\
\hline
\end{tabular}


Table 2. Fatty acid composition of human milk (\%, w/w) (Mean values and standard deviations)

\begin{tabular}{|c|c|c|c|c|c|c|c|}
\hline \multirow[b]{2}{*}{ Fatty acid } & \multicolumn{2}{|c|}{ Colostrum ( $n$ 70) } & \multicolumn{2}{|c|}{ Transitional milk ( $n$ 96) } & \multicolumn{2}{|c|}{ Mature milk ( $n$ 82) } & \multirow[b]{2}{*}{$P$} \\
\hline & Mean & SD & Mean & SD & Mean & SD & \\
\hline SFA & $37 \cdot 9^{a}$ & 3.32 & $41.63^{b}$ & 4.33 & $37 \cdot 18^{\mathrm{a}}$ & 4.92 & $<0.001$ \\
\hline MUFA & $35 \cdot 18^{\mathrm{a}}$ & 2.94 & $32.54^{\mathrm{b}}$ & 3.95 & $35.55^{\mathrm{a}}$ & 3.96 & $<0.001$ \\
\hline PUFA & $26 \cdot 90$ & 2.97 & $25 \cdot 83$ & 3.59 & $27 \cdot 27$ & 5.14 & 0.047 \\
\hline$n-3$ PUFA & $2 \cdot 30$ & 0.45 & $2 \cdot 19$ & 0.58 & $2 \cdot 28$ & 0.69 & 0.430 \\
\hline$n-6$ PUFA & 24.60 & 2.83 & 23.64 & 3.40 & 24.99 & 5.08 & 0.060 \\
\hline$n-6: n-3$ & 11.04 & $2 \cdot 16$ & 11.42 & 3.07 & 11.88 & 3.91 & 0.268 \\
\hline LA:ALA & 20.45 & $6 \cdot 39$ & $18 \cdot 76$ & $6 \cdot 61$ & 18.56 & $7 \cdot 70$ & 0.189 \\
\hline$A A: D H A$ & 1.34 & 0.32 & 1.30 & 0.36 & 1.32 & 0.54 & 0.781 \\
\hline
\end{tabular}

Table 3. Detailed fatty acid profile of SFA

(Mean values and standard deviations)

\begin{tabular}{|c|c|c|c|c|c|c|c|}
\hline \multirow[b]{2}{*}{ Fatty acid } & \multicolumn{2}{|c|}{ Colostrum ( $n$ 70) } & \multicolumn{2}{|c|}{ Transitional milk ( $n$ 96) } & \multicolumn{2}{|c|}{ Mature milk ( $n$ 82) } & \multirow[b]{2}{*}{$P$} \\
\hline & Mean & SD & Mean & SD & Mean & SD & \\
\hline \multicolumn{8}{|l|}{$\mathrm{C} 6: 0$} \\
\hline FA\% & $0.02^{\mathrm{a}}$ & 0.01 & $0.04^{b}$ & 0.01 & $0.05^{b}$ & 0.02 & $<0.001$ \\
\hline$s n-2 \%$ & $25 \cdot 51^{\mathrm{a}}$ & 11.94 & $12 \cdot 06^{\mathrm{b}}$ & $10 \cdot 53$ & $11.56^{\mathrm{b}}$ & $10 \cdot 80$ & $<0.001$ \\
\hline \multicolumn{8}{|l|}{ C8:0 } \\
\hline FA\% & $0.07^{\mathrm{a}}$ & 0.04 & $0.20^{\mathrm{b}}$ & 0.08 & $0.15^{\mathrm{c}}$ & 0.08 & $<0.001$ \\
\hline$s n-2 \%$ & $10 \cdot 61^{a}$ & 7.79 & $6 \cdot 23^{\mathrm{b}}$ & 3.79 & $8 \cdot 25^{\mathrm{b}}$ & 5.01 & $<0.001$ \\
\hline \multicolumn{8}{|l|}{$\mathrm{C} 10: 0$} \\
\hline$F A \%$ & $0.48^{\mathrm{a}}$ & 0.30 & $1.68^{\mathrm{b}}$ & 0.34 & $1.25^{\mathrm{C}}$ & 0.32 & $<0.001$ \\
\hline$s n-2 \%$ & $11 \cdot 72^{\mathrm{a}}$ & 4.64 & $14 \cdot 64^{\mathrm{b}}$ & 4.63 & $15 \cdot 60^{\mathrm{b}}$ & 3.33 & $<0.001$ \\
\hline \multicolumn{8}{|c|}{ C12:0 (lauric) } \\
\hline $\mathrm{FA} \%$ & $2 \cdot 91^{\mathrm{a}}$ & 1.53 & $6.91^{\mathrm{b}}$ & 1.89 & $4 \cdot 20^{\mathrm{c}}$ & 1.48 & $<0.001$ \\
\hline$s n-2 \%$ & $32 \cdot 86^{\mathrm{a}}$ & $4 \cdot 10$ & $35 \cdot 34^{b}$ & $3 \cdot 22$ & $39 \cdot 80^{\mathrm{C}}$ & 2.95 & $<0.001$ \\
\hline \multicolumn{8}{|c|}{ C14:0 (myristic) } \\
\hline $\mathrm{FA} \%$ & $4.77^{\mathrm{a}}$ & 1.64 & $6 \cdot 45^{\mathrm{b}}$ & 2.08 & $3.82^{c}$ & 1.24 & $<0.001$ \\
\hline$s n-2 \%$ & $54 \cdot 81^{a}$ & 3.65 & $55 \cdot 72^{\mathrm{a}}$ & 5.49 & $61.54^{\mathrm{b}}$ & 3.29 & $<0.001$ \\
\hline \multicolumn{8}{|l|}{$\mathrm{C} 15: 0$} \\
\hline$F A \%$ & $0.20^{\mathrm{a}}$ & 0.05 & $0.18^{\mathrm{a}}$ & 0.05 & $0.19^{\mathrm{a}}$ & 0.07 & 0.094 \\
\hline$s n-2 \%$ & $59 \cdot 72^{\mathrm{a}}$ & 6.78 & $63.97^{\mathrm{b}}$ & 5.79 & $68 \cdot 76^{\mathrm{C}}$ & 4.49 & $<0.001$ \\
\hline \multicolumn{8}{|c|}{ C16:0 (palmitic) } \\
\hline $\mathrm{FA} \%$ & $23 \cdot 18^{\mathrm{a}}$ & 1.94 & $20 \cdot 62^{b}$ & 2.01 & $21 \cdot 18^{\mathrm{b}}$ & 2.83 & $<0.001$ \\
\hline$s n-2 \%$ & $74.65^{\mathrm{a}}$ & 4.32 & $75 \cdot 60^{\mathrm{a}}$ & 7.29 & $80 \cdot 75^{\mathrm{b}}$ & 4.54 & $<0.001$ \\
\hline \multicolumn{8}{|l|}{$\mathrm{C} 17: 0$} \\
\hline$F A \%$ & $0.29^{\mathrm{a}}$ & 0.05 & $0.25^{\mathrm{b}}$ & 0.05 & $0.26^{\mathrm{b}}$ & 0.06 & $<0.001$ \\
\hline$s n-2 \%$ & $33 \cdot 13^{a}$ & $6 \cdot 29$ & $36 \cdot 15^{\mathrm{b}}$ & $6 \cdot 14$ & $43 \cdot 36^{\mathrm{C}}$ & $7 \cdot 17$ & $<0.001$ \\
\hline \multicolumn{8}{|c|}{ C18:0 (stearic) } \\
\hline $\mathrm{FA} \%$ & $5 \cdot 50^{\mathrm{a}}$ & 0.88 & $4.98^{\mathrm{b}}$ & 0.76 & $5 \cdot 78^{\mathrm{a}}$ & 0.99 & $<0.001$ \\
\hline$s n-2 \%$ & $10 \cdot 53^{\mathrm{a}}$ & 3.14 & $8 \cdot 16^{\mathrm{b}}$ & $1 \cdot 12$ & $8 \cdot 64^{b}$ & 1.48 & $<0.001$ \\
\hline \multicolumn{8}{|l|}{$\mathrm{C} 20: 0$} \\
\hline FA\% & $0.22^{\mathrm{a}}$ & 0.06 & $0.18^{\mathrm{b}}$ & 0.04 & $0.19^{b}$ & 0.05 & $<0.001$ \\
\hline$s n-2 \%$ & $24.85^{\mathrm{a}}$ & 6.68 & $36.52^{\mathrm{b}}$ & 7.15 & $33.63^{\mathrm{c}}$ & 5.04 & $<0.001$ \\
\hline \multicolumn{8}{|l|}{$\mathrm{C} 22: 0$} \\
\hline$F A \%$ & $0.10^{\mathrm{a}}$ & 0.04 & $0.07^{b}$ & 0.03 & $0.07^{b}$ & 0.04 & $<0.001$ \\
\hline$s n-2 \%$ & $21.08^{a}$ & 9.87 & $33.67^{b}$ & 7.00 & $30 \cdot 25^{c}$ & 6.09 & $<0.001$ \\
\hline \multicolumn{8}{|l|}{$\mathrm{C} 24: 0$} \\
\hline$F A \%$ & $0.17^{a}$ & 0.06 & $0.08^{b}$ & 0.03 & $0.05^{c}$ & 0.04 & $<0.001$ \\
\hline$s n-2 \%$ & $10 \cdot 86^{a}$ & 4.59 & $11.93^{a}$ & $10 \cdot 68$ & $15 \cdot 01^{b}$ & $12 \cdot 54$ & 0.030 \\
\hline
\end{tabular}

$\mathrm{FA} \%$, percentage of total fatty acids; $s n-2 \%$, relative percentage of a specific fatty acid at $s n-2$ position

$\mathrm{a}, \mathrm{b}, \mathrm{c}$ Mean values within a row with unlike superscript letters were significantly different $(P<0.05)$.

\section{Fatty acid and sn-2 fatty acid composition of MUFA}

As shown in Table 4, OA was the absolute dominant MUFA (approximately $30 \%$ of total fatty acids) with the content declined significantly from CM (32.00 (sD 2.64)\%) to TM (29.80 (sD 3.66)\%) and restored again in MM (32.70 (sD 3.76)\%). For other MUFA,
C16 : $1 n-7$ was approximately $2 \%$ and showed a rising tendency among lactation, while $\mathrm{C} 20: 1 n-9, \mathrm{C} 22: 1 n-9$ and NA were lower than $1 \%$ and enriched in CM. NA, the only MUFA mainly located at the $s n-2$ position (54.91-62.87\%), declined by $50 \%$ from CM $(0 \cdot 32 \%)$ to TM (0.11\%) and from TM to MM (0.06\%). 
Table 4. Detailed fatty acid profile of MUFA

(Mean values and standard deviations)

\begin{tabular}{|c|c|c|c|c|c|c|c|}
\hline \multirow[b]{2}{*}{ Fatty acid } & \multicolumn{2}{|c|}{ Colostrum ( $n 70)$} & \multicolumn{2}{|c|}{ Transitional milk ( $n$ 96) } & \multicolumn{2}{|c|}{ Mature milk ( $n$ 82) } & \multirow[b]{2}{*}{$P$} \\
\hline & Mean & SD & Mean & SD & Mean & SD & \\
\hline \multicolumn{8}{|l|}{ C16:1n-7 } \\
\hline$F A \%$ & $1.75^{\mathrm{a}}$ & 0.39 & $2 \cdot 01^{\mathrm{b}}$ & 0.53 & $2 \cdot 18^{\mathrm{b}}$ & 0.50 & $<0.001$ \\
\hline$s n-2 \%$ & $34.55^{\mathrm{a}}$ & 3.91 & $37.30^{\mathrm{b}}$ & 4.63 & $41.50^{\mathrm{C}}$ & 5.30 & $<0.001$ \\
\hline \multicolumn{8}{|c|}{ C18: $1 n-9$ (oleic) } \\
\hline $\mathrm{FA} \%$ & $32.00^{\mathrm{a}}$ & $2 \cdot 64$ & $29 \cdot 80^{\mathrm{b}}$ & 3.66 & $32 \cdot 70^{\mathrm{a}}$ & 3.76 & $<0.001$ \\
\hline$s n-2 \%$ & $13 \cdot 62^{\mathrm{a}}$ & 2.07 & $11 \cdot 70^{\mathrm{b}}$ & 1.65 & $12 \cdot 84^{\mathrm{C}}$ & 1.65 & $<0.001$ \\
\hline \multicolumn{8}{|l|}{ C20: $1 n-9$} \\
\hline FA\% & $0.82^{a}$ & 0.21 & $0.48^{\mathrm{b}}$ & 0.13 & $0.49^{\mathrm{b}}$ & 0.21 & $<0.001$ \\
\hline$s n-2 \%$ & $20 \cdot 40^{\mathrm{a}}$ & $4 \cdot 16$ & $27 \cdot 98^{\mathrm{b}}$ & 6.49 & $25 \cdot 87^{\mathrm{C}}$ & $5 \cdot 10$ & $<0.001$ \\
\hline \multicolumn{8}{|l|}{$\mathrm{C} 22: 1 n-9$} \\
\hline FA\% & $0.29^{a}$ & 0.14 & $0.14^{\mathrm{b}}$ & 0.06 & $0 \cdot 12^{b}$ & $0 \cdot 10$ & $<0.001$ \\
\hline$s n-2 \%$ & $25.63^{\mathrm{a}}$ & 9.43 & $38.60^{\mathrm{b}}$ & $11 \cdot 78$ & $35 \cdot 15^{\mathrm{b}}$ & 11.58 & $<0.001$ \\
\hline \multicolumn{8}{|c|}{ C24:1n-9 (nervonic) } \\
\hline $\mathrm{FA} \%$ & $0.32^{a}$ & 0.14 & $0 \cdot 11^{\mathrm{b}}$ & 0.05 & $0.06^{c}$ & 0.04 & $<0.001$ \\
\hline$s n-2 \%$ & $55.49^{\mathrm{a}}$ & $24 \cdot 30$ & $62 \cdot 87^{b}$ & $27 \cdot 37$ & $54 \cdot 91^{\mathrm{a}}$ & $22 \cdot 71$ & 0.040 \\
\hline
\end{tabular}

FA\%, percentage of total fatty acids; $s n-2 \%$, relative percentage of a specific fatty acid at $s n-2$ position

a,b,c Mean values within a row with unlike superscript letters were significantly different $(P<0.05)$.

Table 5. Detailed fatty acid profile of PUFA

(Mean values and standard deviations)

\begin{tabular}{|c|c|c|c|c|c|c|c|}
\hline \multirow[b]{2}{*}{ Fatty acid } & \multicolumn{2}{|c|}{ Colostrum ( $n$ 70) } & \multicolumn{2}{|c|}{ Transitional milk ( $n$ 96) } & \multicolumn{2}{|c|}{ Mature milk ( $n$ 82) } & \multirow[b]{2}{*}{$P$} \\
\hline & Mean & SD & Mean & SD & Mean & SD & \\
\hline \multicolumn{8}{|l|}{$n-6$ PUFA } \\
\hline \multicolumn{8}{|c|}{ C18:2n-6 (linoleic) } \\
\hline $\mathrm{FA} \%$ & $20 \cdot 66^{a}$ & $2 \cdot 88$ & $21 \cdot 16^{\mathrm{a}}$ & 3.39 & $23 \cdot 15^{\mathrm{b}}$ & 5.07 & $<0.001$ \\
\hline$s n-2 \%$ & $20 \cdot 89^{a}$ & 3.04 & $20 \cdot 03^{\mathrm{a}}$ & 4.42 & $20 \cdot 35^{\mathrm{a}}$ & $3 \cdot 18$ & 0.329 \\
\hline \multicolumn{8}{|l|}{$\mathrm{C} 18: 3 n-6$} \\
\hline FA\% & $0.06^{\mathrm{a}}$ & 0.03 & $0 \cdot 12^{\mathrm{b}}$ & 0.05 & $0.15^{\mathrm{c}}$ & 0.05 & $<0.001$ \\
\hline sn-2\% & $23 \cdot 75^{\mathrm{a}}$ & 8.54 & $23 \cdot 63^{\mathrm{a}}$ & 4.23 & $25 \cdot 48^{\mathrm{a}}$ & 4.55 & 0.078 \\
\hline \multicolumn{8}{|l|}{$\mathrm{C} 20: 2 n-6$} \\
\hline $\mathrm{FA} \%$ & $1 \cdot 38^{\mathrm{a}}$ & 0.29 & $0.67^{\mathrm{b}}$ & 0.10 & $0.46^{\mathrm{c}}$ & 0.08 & $<0.001$ \\
\hline$s n-2 \%$ & $14 \cdot 67^{\mathrm{a}}$ & $2 \cdot 18$ & $18 \cdot 87^{b}$ & 5.02 & $16 \cdot 87^{c}$ & $2 \cdot 17$ & $<0.001$ \\
\hline \multicolumn{8}{|l|}{$\mathrm{C} 20: 3 n-6$} \\
\hline FA\% & $0.75^{a}$ & 0.19 & $0.57^{\mathrm{b}}$ & 0.14 & $0.39^{c}$ & 0.11 & $<0.001$ \\
\hline$s n-2 \%$ & $19 \cdot 15^{\mathrm{a}}$ & $2 \cdot 89$ & $16 \cdot 89^{b}$ & $6 \cdot 01$ & $13 \cdot 47^{\mathrm{C}}$ & $2 \cdot 66$ & $<0.001$ \\
\hline \multicolumn{8}{|c|}{ C20:4n-6 (arachidonic) } \\
\hline FA\% & $0.94^{\mathrm{a}}$ & 0.20 & $0.76^{\mathrm{b}}$ & 0.16 & $0.59^{c}$ & 0.13 & $<0.001$ \\
\hline$s n-2 \%$ & $38.92^{\mathrm{a}}$ & 4.95 & $36 \cdot 30^{\mathrm{b}}$ & 5.64 & $30.84^{c}$ & 5.83 & $<0.001$ \\
\hline \multicolumn{8}{|c|}{ C22: 4n-6 (adrenic) } \\
\hline$F A \%$ & $0.62^{\mathrm{a}}$ & 0.23 & $0.23^{\mathrm{b}}$ & 0.07 & $0.14^{\mathrm{C}}$ & 0.04 & $<0.001$ \\
\hline$s n-2 \%$ & $61 \cdot 32^{\mathrm{a}}$ & 9.51 & $73.35^{\mathrm{b}}$ & $12 \cdot 89$ & $69 \cdot 11^{\mathrm{b}}$ & $15 \cdot 27$ & $<0.001$ \\
\hline \multicolumn{8}{|l|}{$\mathrm{C} 22: 5 n-6$} \\
\hline FA\% & $0.19^{\mathrm{a}}$ & 0.08 & $0 \cdot 13^{\mathrm{b}}$ & 0.04 & $0 \cdot 11^{\mathrm{b}}$ & 0.05 & $<0.001$ \\
\hline$s n-2 \%$ & $46 \cdot 41^{\mathrm{a}}$ & 11.31 & $60 \cdot 55^{\mathrm{b}}$ & $10 \cdot 88$ & $57 \cdot 13^{\mathrm{b}}$ & $13 \cdot 83$ & $<0.001$ \\
\hline \multicolumn{8}{|l|}{$n-3$ PUFA } \\
\hline \multicolumn{8}{|c|}{ C18:3n-3 ( $a$-linolenic) } \\
\hline FA\% & $1 \cdot 10^{\mathrm{a}}$ & 0.37 & $1 \cdot 26^{\mathrm{b}}$ & 0.49 & $1.45^{\mathrm{b}}$ & 0.64 & $<0.001$ \\
\hline$s n-2 \%$ & $23 \cdot 90^{\mathrm{a}}$ & $7 \cdot 14$ & $24 \cdot 11^{\mathrm{a}}$ & 4.01 & $26 \cdot 76^{\mathrm{b}}$ & 4.71 & 0.001 \\
\hline \multicolumn{8}{|l|}{$\mathrm{C} 20: 5 n-3$} \\
\hline $\mathrm{FA} \%$ & $0.09^{a}$ & 0.07 & $0.08^{a}$ & 0.04 & $0 \cdot 10^{\mathrm{a}}$ & 0.07 & 0.248 \\
\hline$s n-2 \%$ & $19 \cdot 07^{\mathrm{a}}$ & 8.42 & $19 \cdot 89^{\mathrm{a}}$ & 5.97 & $18 \cdot 47^{\mathrm{a}}$ & $5 \cdot 37$ & 0.359 \\
\hline \multicolumn{8}{|l|}{$\mathrm{C} 22: 5 n-3$} \\
\hline $\mathrm{FA} \%$ & $0.37^{\mathrm{a}}$ & 0.14 & $0.20^{\mathrm{b}}$ & 0.06 & $0.19^{\mathrm{b}}$ & 0.07 & $<0.001$ \\
\hline$s n-2 \%$ & $62 \cdot 16^{a}$ & 10.05 & $66 \cdot 56^{\mathrm{b}}$ & 12.45 & $62 \cdot 91^{a, b}$ & 14.01 & 0.048 \\
\hline \multicolumn{8}{|c|}{ C22:6n-3 (docosahexaenoic) } \\
\hline $\mathrm{FA} \%$ & $0.74^{a}$ & 0.23 & $0.64^{\mathrm{a}}$ & 0.29 & $0.55^{\mathrm{b}}$ & 0.34 & $<0.001$ \\
\hline$s n-2 \%$ & $60 \cdot 25^{\mathrm{a}}$ & 9.36 & $63.67^{\mathrm{a}}$ & 10.93 & $61 \cdot 89^{\mathrm{a}}$ & 14.41 & 0.187 \\
\hline
\end{tabular}

FA\%, percentage of total fatty acids; $s n-2 \%$, relative percentage of a specific fatty acid at $s n-2$ position.

a,b,c Mean values within a row with unlike superscript letters were significantly different $(P<0.05)$. 


\section{Fatty acid and sn-2 fatty acid composition of PUFA}

As shown in Table 5, the content of LA (approximately $20 \%$ of total fatty acids) predominated among $n-6$ series, and ALA (approximately $1.2 \%$ of total fatty acids) predominated among $n-3$ series. C20 : $2 n-6$ was $1.38 \%$ in CM but fell to approximately $0.6 \%$ in TM and MM, and the other PUFA were lower than $1 \%$ during the three stages. PUFA with a carbon chain length of 18 were more abundant in TM and MM and were preferentially located at the $s n-1,3$ positions (approximately $20 \%$ at the $s n-2$ position). Over lactation stages, LA and ALA showed a significant but small increment, while C18:3n-6 increased by approximately $50 \%$ over the level in CM.

LC-PUFA were enriched in CM, and a relatively low proportion was also found for C20 PUFA at the $s n-2$ position (approximately 20\%) with a higher proportion for AA (30.8438.92\%). C22 PUFA including adrenic acid (C22:4n-6), C22:5n-6, DHA and docosapentaenoic acid (DPA, C22:6n-3), were mainly esterified at the $s n-2$ positions in TAG (approximately $60 \%$ ).

\section{Phospholipid composition over lactation}

PL composition of human milk is shown as absolute amount in Table $6(\mathrm{mg} / 100 \mathrm{~g}$ human milk) and proportion of total PL in Table $7(\%, w / w)$. As shown in Table 6 , the total amount of PE, $\mathrm{PC}$ and SM in human milk were significantly lower in MM (28.10 $(\mathrm{SD} 7 \cdot 86) \mathrm{mg} / 100 \mathrm{~g})$ than in $\mathrm{CM}(35.07$ (SD 10.84) $\mathrm{mg} / 100 \mathrm{~g})$ and TM (35.09 (sD 8.63) mg/100 g). PC appeared at the highest level followed by SM and PE, with the ratio of $4: 2: 1$. As shown in Table 7 , the percentage of $\mathrm{PE}$ remained constant, and different change direction was report as decreasing in PC and increasing in SM.

\section{Discussion}

\section{Fatty acid profile of total and sn-2 position}

The fatty acid composition in Chinese human milk has been well-documented, showing regional disparities interiorly and great differences from Western profile. Studies from representative areas such as Shanghai are needed to conclude the optimal composition of Chinese human milk TAG. Also, the stereo-chemical distribution was less investigated, and most available data only detailed the $s n-2$ fatty acid composition as the percentage of total $s n-2$ fatty acids, without considering the total percentage of each fatty acid, which varied in studies. $s n-2$ profiles were recommended to be expressed as the relative fatty acid in $s n-2$ position to elaborate the positional selectivity of fatty acids ${ }^{(7)}$. Researches also indicated that relative percentages might be better to compare the effect of milk fat on infant development ${ }^{(9)}$. In our present study, fatty acid profile of total and $s n-2$ position was detailed together for a comprehensive understanding of Chinese milk TAG.

\section{SFA}

SFA $(37 \cdot 18-41.63 \%)$ dominated in fatty acid profile over the three lactation stages. The SFA content in mature stage was reported as slightly higher than other studies conducted in China $^{(10,21-23)}$ and slightly lower than conducted in Japan ${ }^{(24)}$, South Korean ${ }^{(25)}$ and some European countries ${ }^{(24)}$ (online Supplementary Table S1). Dietary pattern was commonly considered the major contributor. In general, Western dietary pattern with lower carbohydrate and higher fat than traditional Chinese diet may lead to higher SFA in human milk.

From this study, it has been well-recognised that PA was the dominant SFA in human milk (20.62-23.18\%), and lauric acid (2.91-6.91\%), myristic acid (3.82-6.45\%) and stearic acid (4.98$5.78 \%)$ were also main SFA but with much lower levels that were comparable to previous Chinese data ${ }^{(10,21-23)}$. In our study, PA existed primarily at the $s n-2$ position with a rising tendency over lactation stages $(74.65 \%$ in $\mathrm{CM}, 75.60 \%$ in $\mathrm{TM}$, $80.75 \%$ in MM). A typical $s n-2$ positional preference for PA was also observed in previous studies (online Supplementary Table S2). The Wuxi study reported a similar percentage of $81.29 \%$ from ten $\mathrm{MM}^{(11)}$. And the Chinese multi-centre study from Beijing, Luoyang and Changsha reported a decreasing trend as $77.59 \%$ in CM, $75.56 \%$ in TM and $73.7 \%$ in MM in 1 month and $69.39 \%$ in MM 2 months ${ }^{(9)}$. Similar rising trend with different proportions were reported in foreign studies. A higher level was observed in Spain ${ }^{(7)}$ (80.30\% in CM, 86.25\% in TM, $87.86 \%$ in $\mathrm{MM} ; n$ 12) and a lower level was reported in Italy ${ }^{(8)}(62.00 \%$ in CM, $59 \cdot 11 \%$ in TM, $62 \cdot 86 \%$ in MM; $n$ 8). $s n-2$ PA has been proven to be positively related to improved lipids and $\mathrm{Ca}$ absorption, more faecal SCFA production, better intestinal microbiome development and less gut inflammation ${ }^{(3,9,26)}$.

Similar to other studies, the relative proportion of SFA at the $s n$-2 position increased considerably from C10:0 to C16:0, and the $s n-2$ positional preference was found for C14:0, C15:0 and

Table 6. Phospholipid (PL) composition of human milk ( $\mathrm{mg} / 100 \mathrm{~g}$ human milk) (Mean values and standard deviations)

\begin{tabular}{|c|c|c|c|c|c|c|c|}
\hline \multirow[b]{2}{*}{ PL } & \multicolumn{2}{|c|}{ Colostrum ( $n 70)$} & \multicolumn{2}{|c|}{ Transitional milk ( $n$ 96) } & \multicolumn{2}{|c|}{ Mature milk ( $n$ 82) } & \multirow[b]{2}{*}{$P$} \\
\hline & Mean & SD & Mean & SD & Mean & SD & \\
\hline PE & $4 \cdot 61^{a}$ & $2 \cdot 11$ & $4.79^{a}$ & $2 \cdot 01$ & $3.63^{b}$ & 1.53 & $<0.001$ \\
\hline $\mathrm{PC}$ & $20 \cdot 32^{a}$ & $6 \cdot 61$ & $19.94^{a}$ & 5.35 & $15 \cdot 41^{\mathrm{b}}$ & 5.09 & $<0.001$ \\
\hline SM & $10 \cdot 14^{a, b}$ & 3.39 & $10 \cdot 37^{a}$ & 2.69 & $9 \cdot 07^{\mathrm{b}}$ & 2.52 & 0.007 \\
\hline Total & $35.07^{a}$ & $10 \cdot 84$ & $35.09^{a}$ & 8.63 & $28 \cdot 10^{b}$ & 7.86 & $<0.001$ \\
\hline
\end{tabular}

PE, phosphatidylethanolamine; PC, phosphatidylcholine; SM, sphingomyelin.

${ }^{a, b}$ Mean values within a row with unlike superscript letters were significantly different $(P<0.05)$. 
Table 7. Phospholipid (PL) composition of human milk (\%, w/w) (Mean values and standard deviations)

\begin{tabular}{|c|c|c|c|c|c|c|c|}
\hline \multirow[b]{2}{*}{$\mathrm{PL}$} & \multicolumn{2}{|c|}{ Colostrum ( $n 70)$} & \multicolumn{2}{|c|}{ Transitional milk ( $n$ 96) } & \multicolumn{2}{|c|}{ Mature milk ( $n$ 82) } & \multirow[b]{2}{*}{$P$} \\
\hline & Mean & SD & Mean & SD & Mean & SD & \\
\hline PE & $12 \cdot 86^{\mathrm{a}}$ & $4 \cdot 10$ & $13 \cdot 37^{\mathrm{a}}$ & 3.91 & $12 \cdot 78^{\mathrm{a}}$ & 3.78 & 0.546 \\
\hline PC & $58.06^{\mathrm{a}}$ & $6 \cdot 10$ & $56.85^{a}$ & 5.84 & $54 \cdot 20^{\mathrm{b}}$ & 6.60 & $<0.001$ \\
\hline SM & $29.08^{a}$ & 4.53 & $29 \cdot 77^{\mathrm{a}}$ & 4.42 & $33.03^{\mathrm{b}}$ & $6 \cdot 13$ & $<0.001$ \\
\hline
\end{tabular}

PE, phosphatidylethanolamine; PC, phosphatidylcholine; SM, sphingomyelin.

a,b Mean values within a row with unlike superscript letters were significantly different $(P<0.05)$

C16:0, while other SFA were primarily distributed at the $s n-1,3$ positions $^{(7,8,11)}$. The carbon chain length may be a discriminating factor in distribution of SFA.

\section{MUFA}

The MUFA in our study was comparable to Asian data(10,21-25) but was much lower than Mediterranean studies ${ }^{(7,27)}$, mainly due to the lower level of OA (online Supplementary Table S1). The abundance of OA in Spanish and Italian human milk may be attributed to the high intake of olive oil in classic Mediterranean diet. OA, the main MUFA, plays an important role in the liquidity of human milk required for the formation, transport and metabolism of milk fat globules by reducing the lipid melting point ${ }^{(28)}$.

The MUFA were mainly distributed at the $s n-1,3$ positions with the only exception of NA (54.91-62.87\% at the $s n-2$ position). NA is a low-content MUFA with limited report in previous human milk studies. Increasing numbers of studies have suggested that NA supercharges muscle and brain by forming myelin. The $s n-2$ positional selectivity of NA was also found in several human milk studies $^{(10,11)}$, but only one study reported the accurate percentage as $63.77 \%$ from 10 Wuxi $\mathrm{MM}^{(11)}$. The level of NA found in our study significantly decreased by approximately $50 \%$ from CM (0.32\%) to TM (0.11\%) and from TM to MM (0.06\%). Previous longitudinal Chinese studies indicated a same decrease from CM $(0 \cdot 22-0 \cdot 4 \%)$ to TM $(0 \cdot 08-0 \cdot 13 \%)$, but the NA level was then maintained in MM $(0 \cdot 1-0 \cdot 20 \%)^{(10,21-23)}$. However, MM studies in several Chinese cities including Shanghai also found a low level as $0.05 \%{ }^{(29)}$.

\section{PUFA}

The percentage of PUFA in our study, in agreement with previous Chinese studies ${ }^{(10,21-23)}$, indicated a much higher level than foreign studies mainly due to the high level of LA (online Supplementary Table S1). Asian (0.92-1.33\%, Chinese data included $)^{(10,21-25)}$ and American studies $(1 \cdot 05-1 \cdot 22 \%)^{(24)}$ also found a similar level of ALA in mature stage as our study $(1.45 \%)$, which is nearly twice the level of ALA in European studies $(0 \cdot 62-0 \cdot 75 \%)^{(7,27)}$. The level of DHA in our study was on top of the previous Chinese data $(0 \cdot 22-0.55 \%)$ but much lower than Japan $(0.99 \%)^{(24)}$ and South Korean $(0.67 \%)^{(25)}$ and higher than American reports $(0.17 \%)^{(24)}$. AA was of similar level among different continents. The differences mainly resulted from varied diet intake, and it was well-evidenced that increasing intake of animal and/or marine foods resulted in increment of ALA, and LA was influenced by intake of vegetable oils, while aquatic food intake was correlated with DHA levels in human milk, and AA was found as no clear correlation with dietary interferences ${ }^{(16,30)}$.

With the typical abundance of LA in our study, the $n-6: n-3$ PUFA was found as high as 11 and remained constant over lactation, which was extremely similar to the latest longitudinal human milk study of the neighbouring Chinese city Wuxi ${ }^{(10)}$. The increasing ratios of $n-6: n-3$ were also observed in Chinese as well as Western human milk but not in Japan and South Korean. The dominance of $n-6$ over $n-3$ fatty acids in early life has been ascribed as a contributing factor to childhood obesity and allergies, as $n-6$ fatty acids can promote the differentiation of pre-adipocytes and give rise to pro-inflammatory compounds ${ }^{(31,32)}$. Additional reports also showed that the intake of a high ratio of $n-6: n-3$ fatty acids was correlated with declined neuro-development in offspring ${ }^{(5,33)}$.

In agreement with previous studies, TAG in CM contained lower level of LA and ALA but higher level of LC-PUFA than other two milk stages. Both LA and ALA were mainly distributed at the $s n-1,3$ positions. With the abundance of LA and its $s n-1,3$ positional selectivity, Chinese human milk contains more OA-PA-LA than OA-PA-OA ${ }^{(34)}$, while OA-PA-OA is the most abundant TAG in Western human milk ${ }^{(35)}$. Commercial formulas based on foreign studies may be not suitable for Chinese babies.

The three most abundant PUFA in human brain are DHA, AA and adrenic acid, serving as essential bio-active substances for motor and cognitive development along with immune functions in infants. DPA has not been extensively studied because of the limited availability of the pure compound, but the available data suggest that it has beneficial effects in inflammation and immune response modulation and spatial learning ${ }^{(36)}$. The study from Spain ${ }^{(7)}$ showed a relatively lower proportion of DHA at the $s n$-2 position (52.63-61.39\%) and a higher AA (43.27-47.85\%) than our data (60.25-61.89\% for DHA, 30.84$38.92 \%$ for AA). Current reported result from Wuxi, China ${ }^{(11)}$, showed that the relative $s n-2$ proportion of DHA (63.23\%) and AA (39.65\%) in MM was similar to ours. Possible mechanisms for the distribution include better absorption ${ }^{(37,38)}$, improved oxidative stability $^{(39)}$ and their enrichment in brain tissues ${ }^{(40,41)}$.

The levels of adrenic acid and DPA were less investigated, and our data in each lactation stage were similar to a multicentre Chinese human milk study ( $n$ 477) in 2016 ${ }^{(22)}$. However, available data showed conflicting positional distribution patterns for the two fatty acids. Adrenic acid (32.42\% at the $s n-2$ 
position) and DPA (28.24\% at the $s n-2$ position) were observed with preferable distribution at $s n-1,3$ positions in the Wuxi study $^{(11)}$, while our study, in agreement with the Spanish study $^{(7)}$, showed an $s n-2$ positional selectivity (higher than $60 \%$ ) for both the fatty acids (online Supplementary Table S2). Another Chinese study with 309 human milk samples determined also indicated that DPA and adrenic acid were both preferential esterified at the $s n$ - 2 positions (no accurate relative percentage reported ${ }^{(10)}$. Thus, additional studies should be performed on the LC-PUFA distribution.

\section{Phospholipids}

Human milk PL studies were relatively limited and varied in results all over the world. Total PL content in human milk ranged between 9.8 and $47.4 \mathrm{mg} / 100 \mathrm{~g}$, with SM (28.9-43.3\%), PC (19.0-38.4\%) and PE (5.9-36.1\%) found in most studies as the three most abundant $\mathrm{PL}^{(13,14,22)}$. Therefore, only the three main PL were measured in this study.

The total amount of PL in our study decreased significantly from $35.07 \mathrm{mg} / 100 \mathrm{~g}$ in CM to $28.10 \mathrm{mg} / 100 \mathrm{~g}$ in MM, indicating reduced bio-synthesis of PL in the later stage of lactation. Recent Western studies found a much lower level of PL (13.5-16.8 mg/ $100 \mathrm{~g}$ in $\mathrm{CM}$ and $9 \cdot 8-19 \cdot 2 \mathrm{mg} / 100 \mathrm{~g}$ in $\mathrm{MM})^{(13,14)}$, but the latest Chinese study from Beijing, Guangzhou and Suzhou ${ }^{(22)}$ reported a comparable level of PL as $33.0-38.9 \mathrm{mg} / 100 \mathrm{ml}$ in CM and $22.3-26.0 \mathrm{mg} / 100 \mathrm{ml}$ in $\mathrm{MM}$. The decline of PL in human milk was found concomitant with the maturation of digestion system in infants and responsible for the decrease in the thickness of the membrane that surrounds the fat globule in human milk ${ }^{(42)}$.

The content and relative content order of the three PL differed in previous studies, and most Western studies reported the content order as $\mathrm{SM}>\mathrm{PC}>\mathrm{PE}^{(13,14)}$. The order of $\mathrm{PC}>\mathrm{SM}>\mathrm{PE}$ was shown in this study, similar to the Chinese multi-centre study mentioned earlier ${ }^{(22)}$. However, compared to the total population data from the Chinese study (PC 8.2-12.0 mg/100 ml, SM $7 \cdot 2-9.0 \mathrm{mg} / 100 \mathrm{ml}$, PE $6.4-8.5 \mathrm{mg} / 100 \mathrm{ml})$, the amount of PC $(15.41-20.32 \mathrm{mg} / 100 \mathrm{~g}$ ) was much higher, and SM (9.07$10 \cdot 14 \mathrm{mg} / 100 \mathrm{~g}$ ) showed a similar content while the amount of PE (3.63-4.61 mg/100 g) was much lower in our study.

Each of the three PL showed a decline in the absolute content with the prolonged lactation, which was consistent with previous studies. When reported as the relative proportion of total PL, PE remained stable while $\mathrm{PC}$ and SM showed decreasing and increasing trend, respectively, from CM to MM stage in our study. The Chinese multi-centre study ${ }^{(22)}$ did not detail the percentage data, and in Western studies, PC showed an increment over lactation, while varied trend was observed in different studies for PE (stable/increasing) and SM (stable/increasing/decreasing). More research should be performed on the PL composition along with possible mechanisms and consequent influences.

\section{Conclusions}

The fatty acid profile of total and $s n-2$ position and the composition of main PL were determined in 248 human milk samples collected longitudinally from Shanghai, a representative city for human milk studies. We observed significant changes in the composition of fatty acids, $s n-2$ fatty acids and PL over lactation, while the positional distribution pattern ( $s n-2$ or $s n-1,3)$ remained relatively consistent. Compared to Western studies, LA was more common in our study, which contributed to the high ratio of $n-6: n-3$ PUFA and the relative abundance of OA-PA-LA with its $s n-1,3$ selectivity. While the majority of unsaturated fatty acids were esterified at the $s n-1,3$ positions, long-chain unsaturated fatty acids closely related to brain and immune development were enriched in CM and mainly distributed at the $s n-2$ position. For the three dominant PL, the content order of $\mathrm{PC}>\mathrm{SM}>\mathrm{PE}$ was shown, with the relative percentage of $\mathrm{PC}, \mathrm{SM}$ and $\mathrm{PE}$ decreasing, increasing and remaining constant across the three lactation stages, respectively. Results in this study provided comprehensive information for future infant formula design with optimal lipid profile close to Chinese human milk. Further studies are still needed to focus on the theory behind these specific profiles and the corresponding functions.

\section{Acknowledgements}

This study was supported by Abbott Nutrition Research \& Development Center, Shanghai, China.

Y. G., M. C., Y. M. and F. T. conceived and designed the study protocols. B. W., L. Z. and L. S. conducted the sample collection. R. G. and K. W. conducted the determinations and analysed the data. K. W. wrote the manuscript. M. C. and Y. G. were primarily responsible for the final contents. All the authors read and approved the final manuscript.

None of the authors has any conflicts of interest to declare.

\section{Supplementary material}

For supplementary material/s referred to in this article, please visit https://doi.org/10.1017/S0007114518002994

\section{References}

1. Kramer MS \& Kakuma R (2004) The optimal duration of exclusive breastfeeding: a systematic review. Adv Exp Med Biol 554, 63-77.

2. Innis SM (2011) Dietary triacylglycerol structure and its role in infant nutrition. Adv Nutr 2, 275-283.

3. Bar-Yoseph F, Lifshitz Y \& Cohen T (2013) Review of $s n-2$ palmitate oil implications for infant health. Prostaglandins Leukot Essent Fatty Acids 89, 139-143.

4. Willatts P, Forsyth S, Agostoni C, et al. (2013) Effects of longchain PUFA supplementation in infant formula on cognitive function in later childhood. Am J Clin Nutr 98, 536S-542S.

5. Jumbe T, Comstock SS, Harris WS, et al. (2016) Whole-blood fatty acids are associated with executive function in Tanzanian children aged 4-6 years: a cross-sectional study. Br J Nutr 116, 1537-1545.

6. Strandvik B, Ntoumani E, Lundqvist-Persson C, et al. (2016) Long-chain saturated and monounsaturated fatty acids associate with development of premature infants up to 18 months of age. Prostaglandins Leukot Essent Fatty Acids 107, 43-49.

7. Lopez-Lopez A, Lopez-Sabater MC, Campoy-Folgoso C, et al. (2002) Fatty acid and $s n-2$ fatty acid composition in human 
milk from Granada (Spain) and in infant formulas. Eur I Clin Nutr 56, 1242-1254.

8. Haddad I, Mozzon M \& Frega NG (2012) Trends in fatty acids positional distribution in human colostrum, transitional, and mature milk. Eur Food Res Technol 235, 325-332.

9. Jiang T, Liu B, Li J, et al. (2018) Association between sn-2 fatty acid profiles of breast milk and development of the infant intestinal microbiome. Food Funct 9, 1028-1037.

10. Qi C, Sun J, Xia Y, et al. (2018) Fatty acid profile and the $s n-2$ position distribution in triacylglycerols of breast milk during different lactation stages. I Agric Food Chem $\mathbf{6 6}$ 3118-3126.

11. Sun C, Wei W, Su H, et al. (2018) Evaluation of $s n$-2 fatty acid composition in commercial infant formulas on the Chinese market: a comparative study based on fat source and stage. Food Chem 242, 29-36.

12. Straarup EM, Lauritzen L, Faerk J, et al. (2006) The stereospecific triacylglycerol structures and fatty acid profiles of human milk and infant formulas. I Pediatr Gastroenterol Nutr 42, 293-299.

13. Cilla A, Diego Quintaes K, Barbera R, et al. (2016) Phospholipids in human milk and infant formulas: benefits and needs for correct infant nutrition. Crit Rev Food Sci 56, 1880-1892.

14. Verardo V, Gomez-Caravaca AM, Arraez-Roman D, et al. (2017) Recent advances in phospholipids from colostrum, milk and dairy by-products. Int J Mol Sci 18, 173-196.

15. Sosa-Castillo E, Rodriguez-Cruz M \& Molto-Puigmarti C (2017) Genomics of lactation: role of nutrigenomics and nutrigenetics in the fatty acid composition of human milk. Br J Nutr $\mathbf{1 1 8}$ 161-168.

16. Innis SM (2014) Impact of maternal diet on human milk composition and neurological development of infants. Am J Clin Nutr 99, 734S-741S

17. Bravi F, Wiens F, Decarli A, et al. (2016) Impact of maternal nutrition on breast-milk composition: a systematic review. $\mathrm{Am}$ J Clin Nutr 104, 646-662.

18. Folch J, Lees M \& Sloane Stanley GH (1957) A simple method for the isolation and purification of total lipides from animal tissues. I Biol Chem 226, 497-509.

19. Luddy FE, Barford RA, Herb SF, et al. (1964) Pancreatic lipase hydrolysis of triglycerides by a semimicro technique. J Am Oil Chem Soc 41, 693-696.

20. López-López A, Castellote-Bargalló AI \& López-Sabater MC (2001) Comparison of two direct methods for the determination of fatty acids in human milk. Chromatographia 54, 743747.

21. Urwin HJ, Zhang J, Gao Y, et al. (2013) Immune factors and fatty acid composition in human milk from river/lake, coastal and inland regions of China. Br J Nutr 109, 1949-1961.

22. Giuffrida F, Cruz-Hernandez C, Bertschy E, et al. (2016) Temporal changes of human breast milk lipids of Chinese mothers. Nutrients $\mathbf{8}, 715-733$.

23. Jiang J, Wu K, Yu Z, et al. (2016) Changes in fatty acid composition of human milk over lactation stages and relationship with dietary intake in Chinese women. Food Funct 7, 3154-3162.

24. Yuhas R, Pramuk K \& Lien EL (2006) Human milk fatty acid composition from nine countries varies most in DHA. Lipids 41, 851-858.
25. Kim H, Kang S, Jung BM, et al. (2017) Breast milk fatty acid composition and fatty acid intake of lactating mothers in South Korea. Br J Nutr 117, 556-561.

26. Miles EA \& Calder PC (2017) The influence of the position of palmitate in infant formula triacylglycerols on health outcomes. Nutr Res 44, 1-8.

27. Grote V, Verduci E, Scaglioni S, et al. (2016) Breast milk composition and infant nutrient intakes during the first 12 months of life. Eur J Clin Nutr 70, 250-256.

28. Jensen RG (1999) Lipids in human milk. Lipids 34, 1243-1271.

29. Li J, Fan Y, Zhang Z, et al. (2009) Evaluating the trans fatty acid, CLA, PUFA and erucic acid diversity in human milk from five regions in China. Lipids 44, 257-271.

30. Chung MY (2014) Factors affecting human milk composition. Pediatr Neonatol 55, 421-422.

31. Allhaud G, Guesnet P \& Cunnane SC (2008) An emerging risk factor for obesity: does disequilibrium of polyunsaturated fatty acid metabolism contribute to excessive adipose tissue development? Br I Nutr 100, 461-470.

32. Nwaru BI, Erkkola M, Lumia M, et al. (2012) Maternal intake of fatty acids during pregnancy and allergies in the offspring. $\mathrm{BrJ}$ Nutr 108, 720-732.

33. Andrade-da-Costa B, Isaac A, Silva E, et al. (2017) Low omega 6/omega 3 fatty acid ratio in maternal diet favors leukemia inhibitory factor (LIF) gene transcription in the offspring's neural cells. Glia 65, E250-E250.

34. Tu A, Ma Q, Bai H, et al. (2017) A comparative study of triacylglycerol composition in Chinese human milk within different lactation stages and imported infant formula by SFC coupled with Q-TOF-MS. Food Chem 221, 555-567.

35. Haddad I, Mozzon M, Strabbioli R, et al. (2012) A comparative study of the composition of triacylglycerol molecular species in equine and human milks. Dairy Sci Technol 92, 37-56.

36. Dyall SC (2015) Long-chain omega-3 fatty acids and the brain: a review of the independent and shared effects of EPA, DPA and DHA. Front Aging Neurosci 7, 52-66.

37. Christensen MS, Hoy CE, Becker CC, et al. (1995) Intestinal absorption and lymphatic transport of eicosapentaenoic (EPA), docosahexaenoic (DHA), and decanoic acids: dependence on intramolecular triacylglycerol structure. Am J Clin Nutr 61, 56-61.

38. Cruz-Hernandez C, Thakkar SK, Moulin J, et al. (2012) Benefits of structured and free monoacylglycerols to deliver eicosapentaenoic (EPA) in a model of lipid malabsorption. Nutrients 4, 1781-1793.

39. Wijesundera C (2008) The influence of triacylglycerol structure on the oxidative stability of polyunsaturated oils. Lipid Technol 20, 199-202.

40. Christensen MM \& Hoy CE (1997) Early dietary intervention with structured triacylglycerols containing docosahexaenoic acid. Effect on brain, liver, and adipose tissue lipids. Lipids $\mathbf{3 2}$, 185-191.

41. Christensen MM, Lund SP, Simonsen L, et al. (1998) Dietary structured triacylglycerols containing docosahexaenoic acid given from birth affect visual and auditory performance and tissue fatty acid profiles of rats. J Nutr 128, 1011-1017.

42. Bitman J, Wood DL, Mehta NR, et al. (1984) Comparison of the phospholipid composition of breast milk from mothers of term and preterm infants during lactation. Am J Clin Nutr 40, 1103-1119. 